\title{
Giant Platelet Count
}

National Cancer Institute

\section{Source}

National Cancer Institute. Giant Platelet Count. NCI Thesaurus. Code C74728.

The determination of the number of giant platelets present in a sample. 